\title{
The role of bone morphogenetic proteins in ovarian function
}

\author{
S. Shimasaki, R. K. Moore, G. F. Erickson and F. Otsuka
}

Department of Reproductive Medicine, University of California San Diego, School of Medicine, 9500 Gilman Drive, La Jolla, CA 92093-0633, USA

\begin{abstract}
Bone morphogenetic proteins (BMPs) represent the largest subclass of growth factors in the transforming growth factor $\beta$ (TGF- $\beta$ ) superfamily. BMPs have proven to be multifunctional regulators of a wide variety of biological processes in numerous types of cell and tissue. The role of inhibins, activins and TGF- $\beta$ s (which also belong to the TGF- $\beta$ superfamily) in reproduction has been studied extensively over the last 15 years. However, there were no reports on the role of BMPs in the mammalian ovary until 1999 when we reported an intrinsic ovarian BMP system replete with BMP ligands, receptors and novel biological functions. Since this report it has become clear that the BMP system plays an important role in the regulation of ovarian function, evidenced by the ability of BMPs to control granulosa cell proliferation and cytodifferentiation, as well as oocyte development. The physiological relevance of the BMP system has recently been highlighted by the discovery that genetic mutations in the BMP-15 ligand or the BMP type IB receptor lead to critical aberrations in folliculogenesis and ovulation. This review provides a current overview of the rapidly emerging field of the BMP system in mammalian ovarian function.
\end{abstract}

\section{Introduction}

TGF- $\beta$ superfamily: the bone morphogenetic proteins

Bone morphogenetic proteins (BMPs) were originally isolated from bovine and human bone as proteins that induce bone and cartilage formation in ectopic extra-skeletal sites in vivo (Wozney et al., 1988). The deduced amino acid sequences from the corresponding CDNAs revealed that these proteins are structurally related to transforming growth factor $\beta$ (TGF- $\beta$ ). To date, more than 30 members of the TGF- $\beta$ superfamily have been identified in various species, including sea urchins, frogs, Drosophila, chickens, mice, rats and humans (Griffith et al., 1996; Kawabata and Miyazono, 2000). Most of these members were identified by a homology-based PCR cloning strategy and designated simply as related to the name of the CDNA clone from which PCR primer sequences were selected. Therefore, overlapping names have been given to the same molecule (for example BMP-7/OP-1, BMP-6/Ngr-1, BMP-3b/GDF-10, BMP-13/GDF-6, BMP-15/GDF-9B). In addition, there is no direct evidence 
that all molecules designated as BMPs can induce cartilage and bone formation; thus, the nomenclature is misleading and a proper nomenclature for these molecules is required. Indeed, it is well established that the BMPs regulate biological processes that are as diverse as cell proliferation, apoptosis, differentiation, determination of cell fate and morphogenesis.

\section{Common structure of TGF- $\beta$ superfamily members}

All TGF- $\beta$ superfamily members are synthesized as large precursor proteins that are approximately three times larger than the mature protein (Massagué et al., 1994). The precursors are first dimerized and then undergo proteolytic processing at RXXR sites to yield mature active dimeric proteins composed of the carboxy terminal segments of the precursors. The BMPs are distinguished from other members by having seven, rather than nine, conserved cysteines in the mature protein region. Crystallography of the mature molecule, such as TGF- $\beta 2$ (Schlunegger and Grütter, 1992) and BMP-7 (Griffith et al., 1996), showed that six of the seven common cysteines are closely linked within the subunit to a rigid structure known as a cysteine knot, and the remaining cysteine residue is necessary for disulphide bonding of the two monomers into a dimer (Vitt et al., 2001). BMP-15 and growth differentiation factor 9 (GDF-9) are two closely related molecules which form a distinct subset of the TGF- $\beta$ superfamily (Dube et al., 1998). A major structural distinction of BMP-15 and GDF-9 from other TGF- $\beta$ superfamily members is that they lack the cysteine residue involved in inter-subunit disulphide bonding (McPherron and Lee, 1993; McGrath et al., 1995; Dube et al., 1998). It is not known whether BMP-15 and GDF-9 exist as monomers or form non-covalent dimers.

\section{Receptors of TGF- $\beta$ superfamily members}

Receptors for TGF- $\beta$ superfamily members comprise a family of two closely related cell surface receptor subtypes: the type I and type II receptors (Miyazono et al., 2001). In mammals, seven type I and five type II receptors have been characterized to date. Both types of the receptor are structurally similar and possess serine/threonine kinase domains in their intracellular domains. The type $I I$ receptor kinases are constitutively active without ligand stimulation. The dimeric TGF- $\beta$ superfamily members bind to a heterotetrameric complex of two type I and two type II receptors. Type I receptors, but not type II receptors, have a region rich in glycine and serine residues (GS domain) in the juxtamembrane domain. In the case of TGF- $\beta$ s and activins, it is thought that the ligand first binds specific type II receptors followed by the recruitment of type I receptors into the complex. The BMP receptor system is somewhat different in that both type II receptors and type I receptors independently have low affinity for the ligand, but together they can achieve high affinity binding (Liu et al., 1995). Once activated, all type II receptors phosphorylate type I receptors at five serine and threonine residues located in a cluster in the GS domain. The phosphorylated type I receptors subsequently trigger downstream signalling cascades.

\section{Signal transduction of TGF- $\beta$ superfamily members}

The signalling pathways of the TGF- $\beta$ superfamily members have been studied extensively (Hogan, 1996; Heldin et al., 1997; Miyazono et al., 2001). In the signalling pathway, the phosphorylated type I receptors interact with and phosphorylate downstream signalling molecules known as Smads, namely Smad1, Smad2, Smad3, Smad5 and Smad8. Different members of the Smad family play different roles in signalling. For example, overexpression of Smad1 in Xenopus embryos mimics the effects of BMP-4 (ventral mesoderm induction) (Graff et al., 1996; Thomsen, 1996), whereas overexpression of Smad2 mimics the effects of Vg-1 
(dorsal mesoderm induction) (Graff et al., 1996). As such, these members of the Smad family are known as 'pathway-restricted Smads' and are present in the cytoplasm as homotrimers, After pathway-restricted Smads are phosphorylated by type I receptors, they interact with another Smad molecule termed Smad4. Smad4 functions as a 'common-mediator Smad' to form a hetero-oligomeric complex with one of the pathway-restricted Smads. The complex is then translocated to the nucleus, where it binds either directly or in complex with other component(s) to the target DNA, and affects transcription of specific genes. More than 40 proteins are known to interact with Smads in various types of cell (Miyazono et al., 2001). These Smad partner proteins can regulate membrane anchoring of Smads, ubiquitin-dependent protein degradation and transcription by Smads. As the number of type I and type II receptors and Smad proteins is limited, and yet a wide range of biological activities are elicited by a given member of the TGF- $\beta$ superfamily, the role for Smad partner proteins in the signalling pathway must be physiologically important. It is also known that Smad6 and Smad7 prevent the phosphorylation and signalling activity of pathway-restricted Smads by binding to the type I receptors (Miyazono et al., 2001). Thus, these Smads act as inhibitors of the bioactivity of TGF- $\beta$ superfamily ligands.

Although Smads are key signalling molecules of the TGF- $\beta$ superfamily members, other signalling pathways are present concurrently (Miyazono et al., 2001). Examples include TGF- $\beta$-activated kinase (TAK-1), a member of the mitogen-activated protein kinase kinase kinase (MAPKKK) family, which is activated by BMP-4 or TGF- $\beta$, and members of the Ras or Rac families of small GTP-binding proteins, which also have been implicated in TGF- $\beta$ signalling. Moreover, the extracellular signal-regulated kinase-1 (ERK1) and -2 (ERK2) and stress-activated protein kinase (SAPK)/Jun- $\mathrm{N}$-terminal kinase (JNK) have also been linked to TGF- $\beta$ signal transduction in some types of cell. Thus, there is certainly crosstalk between different signalling pathways in the TGF- $\beta$ superfamily.

\section{BMPs in non-ovarian tissues}

Besides regulating bone formation in vivo, studies have demonstrated that BMPs are multifunctional regulators in a wide array of biological processes in both vertebrates and invertebrates (Kingsley, 1994; Hogan, 1996). In addition to bone, there is evidence that expression of BMP genes is high in the kidney (BMP-3, -4 and -7 ), lung (BMP-3, $-4,-5$ and -6 ), small intestine (BMP-3 and -7), heart (BMP-2, $-4,-6$ and -7 ), limb bud (BMP-2, $-4,-5$ and -7 ) and teeth (BMP-3, -4 and -7 ) and that they can regulate the cellular homeostasis by paracrine mechanisms (Lyons et al., 1989, 1990).

\section{Expression of BMP ligands and receptors in the ovary}

To date, the mRNAs encoding BMP-2, -3, -3b, $-4,-6,-7,-15$ and GDF-9, and BMP receptor type IA (BMPR-IA), type IB (BMPR-IB) and type II (BMPR-II) have been identified in the ovary of various mammals by northern blot or in situ hybridization analysis. The growing number of BMP ligands and receptors identified in ovarian cells is indicative of a role of BMPs in controlling ovarian function.

\section{$B M P-2, B M P-3$ and $B M P-3 b$}

Expression of BMP-2, -3 and $-3 \mathrm{~b}$ mRNAs were first demonstrated in the adult rat ovary by northern blot analysis, and highest expression was of BMP-2 mRNA (Takao et al., 1996). In human ovaries, BMP-3 mRNA is strongly detectable by northern blot analysis, whereas expression of BMP-2 mRNA is very weak and BMP-3b mRNA is undetectable (Hino et al., 
1996). BMP-3 mRNA expression was also identified in human granulosa-luteal cells (Jaatinen et al., 1996). During in vitro culture of human granulosa-luteal cells, the basal steady-state expression of BMP-3 mRNA increased spontaneously, whereas treatment of these cells with hCG markedly suppressed BMP-3 mRNA (Jaatinen et al., 1996). In addition, 8-bromo-cAMP (8-Br-CAMP) and 12-0-tetradecanoylphorbol-13-acetate decreased BMP-3 mRNA expression in these cells, indicating that BMP-3 mRNA expression can be regulated by pathways mediated by both protein kinase $\mathrm{A}$ (PKA) and protein kinase C (PKC) in these cells (Jaatinen et al., 1996).

\section{BMP-4 and BMP-7}

Studies on the expression of mRNA encoding BMP-4 and -7 by in situ hybridization in rat ovaries revealed that BMP-4 and -7 co-localize to the theca interstitial cells and that the expression changes during folliculogenesis (Shimasaki et al., 1999). Interestingly, the BMP-4 and -7 mRNAs are strongly expressed in theca interstitial cells of dominant follicles but are much less abundant in theca interstitial cells of atretic follicles. This finding underscores the potential importance of the regulated co-expression of BMP-4 and -7 in follicle development and demise. BMP-4 and -7 are also expressed in the surface epithelium and in some corpora lutea (Shimasaki et al., 1999), indicating that these BMPs may also regulate functions in these tissues.

\section{$B M P-6$}

In the adult mouse ovary, mRNA encoding BMP-6 is highly expressed in immature and mature oocytes, and in lower amounts in the granulosa cells (Lyons et al., 1989; Elvin et al., 2000a), BMP-6 mRNA has also been found in adult rat oocytes, granulosa cells, surfac epithelium and some corpora lutea (G. F. Erickson and S. Shimasaki, unpublished). The BMP-6 mRNA signal is extremely strong in the oocytes and granulosa cells of healthy Graafian follicles. It should be noted that the intense expression of BMP-6 mRNA begins in preantral follicles at the secondary stage. With respect to granulosa cells, BMP- 6 mRNA appears to be uniformly present in all granulosa cells, that is, membrana, periantral and cumulus granulosa cells.

\section{$B M P-15$}

The expression of BMP-15 is confined exclusively to the oocyte in mice, rats and humans (Dube et al., 1998; Laitinen et al., 1998; Aaltonen et al., 1999; Jaatinen et al., 1999; Otsuka et al., 2000). In situ hybridization studies in the mouse revealed that BMP-15 mRNA expression starts in oocytes of primary follicles and is strongly expressed in oocytes throughout the preantral (gonadotrophin-independent) and antral (gonadotrophin-dependent) stages of folliculogenesis (Dube et al., 1998). Otsuka et al. (2000) demonstrated that BMP-15 mRNA and protein are co-expressed in oocytes, beginning in primary follicles throughout the preovulatory stage. Further studies by Otsuka and Shimasaki (2002) found that kit ligand inhibits BMP-15 mRNA expression in oocytes, whereas BMP-15 stimulates kit ligand mRNA expression in granulosa cells. This was the first demonstration of a paracrine negative feedback loop between the oocyte and granulosa cells.

\section{GDF-9}

As for BMP-15, the oocyte is the unique site of ovarian GDF-9 mRNA and protein expression in a variety of species including humans, rats, mice, sheep and cows (McGrath et al., 1995; Dong et al., 1996; Fitzpatrick et al., 1998; Aaltonen et al., 1999; Bodensteiner et al., 1999; Elvin et al., 1999a; Erickson and Shimasaki, 2000; Elvin et al., 2000a). GDF-9 mRNA and 
protein are co-expressed in oocytes at all stages of follicular development, except for primordial follicles in mice, rats and humans (McGrath et al., 1995; Dong et al., 1996; Aaltonen et al., 1999; Elvin et al., 1999a). However, in ovine and bovine ovaries, GDF-9 mRNA could be detected as early as the primordial follicle stage (Bodensteiner et al., 1999). GDF-9 mRNA expression in human oocytes closely resembles that of BMP-15 mRNA but begins slightly earlier (at small primary follicles) than that of BMP-15, the expression of which begins at the large primary follicle stage (Aaltonen et al., 1999).

\section{BMP receptors}

The first comprehensive investigation of BMP type I and type II receptors in the ovary revealed that this tissue is the main site of expression of these receptors (Shimasaki et al., 1999), supporting the hypothesis that BMPs are important to ovarian physiology. The mRNA for $B M P$ receptor IA (BMPR-IA) is expressed in granulosa cells and oocytes in adult rat ovaries (Shimasaki et al., 1999). A relatively high BMPR-IA mRNA content can be detected in oocytes, whereas the content in granulosa cells is relatively low in the same follicles of healthy and atretic follicles. In addition, rat ovaries express BMPR-IB mRNA in the oocytes and in all the granulosa cells of healthy follicles after the primary stage. The expression of BMPR-II mRNA was detected exclusively in granulosa cells, beginning in the secondary follicle, that is, when there are two layers of granulosa cells. During the stages of preantral and antral follicle development, very high amounts of BMPR-II mRNA are present in all granulosa cells, that is, membrana, periantral and cumulus cells (Shimasaki et al., 1999).

Baird and colleagues investigated the expression of BMP receptor proteins in the sheep ovary by immunohistochemical analysis (Souza et al., 2002). All three BMP receptors (BMPRIA, -IB and -II) are expressed strongly in the granulosa cell layer of follicles from the primary to the late antral stages of development. These receptors are also expressed in the oocytes, corpora lutea and ovarian surface epithelia, whereas they are expressed at a lesser extent in the theca cells of antral follicles (Souza et al,+ 2002 ).

\section{Role of BMPs in regulating follicle growth and development}

\section{BMP-4 and BMP-7}

A major concept of ovarian physiology is that FSH stimulates the granulosa cells of growing follicles to produce increasing amounts of oestradiol during the follicular phase of the ovarian cycle. However, progesterone synthesis in response to FSH is inhibited until the periovulatory period when it increases suddenly. In contrast to the steroidogenic properties of granulosa cells in vivo, granulosa cells from early antral follicles cultured in vitro in the presence of FSH secrete copious amounts of both oestradiol and progesterone. These findings led to the concept that there is a luteinization inhibitor in vivo which selectively inhibits FSH-dependent follicular progesterone but not oestradiol production by granulosa cells. The elucidation of the biological effects of BMP-4 and -7 in the ovary identified these factors as the first candidate molecules the biological activities of which are consistent with the long sought luteinization inhibitor (Shimasaki et al., 1999).

The addition of BMP-4 and -7 to cultures of rat primary granulosa cells from early antral follicles had no effect on steroid production when added alone. Interestingly, the addition of both BMP-4 and -7 led to an increase in FSH-induced oestradiol production, but decreased FSH-induced progesterone production (Shimasaki et al., 1999). Thus, BMP-4 and -7 were identified as the first molecules that can differentially modulate FSH action in a manner that reflects normal follicle steroidogenesis during the oestrous cycle. Examination of the 
cellular mechanisms by which BMP-7 differentially regulates FSH action in steroidogenesis demonstrated that BMP-7 enhances P450 aromatase (P450arom), but suppresses steroidogenic acute regulatory protein (StAR) mRNA expression induced by FSH (Lee et al., 2001). However, BMP-7 did not change FSH-induced amounts of mRNA P450 side-chain cleavage (P450scc) or $3 \beta$-hydroxysteroid dehydrogenase ( $3 \beta$-HSD). These findings indicate that BMP-7 stimulation and inhibition of P450arom and StAR mRNA expression, respectively, may play a role in the mechanisms underlying the differential regulation of oestradiol and progesterone production. BMP-7 was also found to exhibit mitotic properties on granulosa cells, demonstrated by increases in granulosa cell thymidine incorporation and the number of cells (Lee et al., 2001).

Lee et al. (2001) investigated the effects of BMP-7 on folliculogenesis and ovulation in the rat to establish the physiological relevance of BMP-7 function in vivo. Administration of BMP-7 into the ovarian bursa caused a decrease in the number of primordial follicles and, simultaneously, an increase in the number of primary, secondary and antral follicles. These findings indicate that BMP-7 may act to facilitate the recruitment of primordial follicles into the growing follicle pool. Importantly, administration of BMP-7 caused a pronounced decrease in plasma progesterone concentrations, confirming the relevance in vivo of the in vitro effects of BMP-7 on progesterone production. Furthermore, a significant decrease in the number of ovulated oocytes was observed in the BMP-7-treated ovaries as compared with the untreated contralateral control ovaries. Therefore, these findings could target thecaderived BMP-7 in the promotion of recruitment and thereby in determining ovary reserve.

Dooley et al. (2000) used human ovarian theca-like tumour (HOTT) cells which express BMPR-IA, BMPR-IB and BMPR-II to examine the impact of BMP-4 on theca cell function. In this system, BMP-4 inhibited forskolin-stimulated $17 \alpha$-hydroxylase expression without changing the expression of StAR, P450scc or $3 \beta$-HSD induced by forskolin. This selective regulation of BMP-4 is likely to lead to an alternation of steroid production induced by forskolin resulting in increased progesterone accumulation and decreased $17 \alpha$-hydroxyprogesterone and androstenedione production, although the addition of BMP-4 alone (without forskolin) exhibited only a modest decrease in androstenedione secretion (Dooley et al., 2000). Thus, BMP-4 led to the production of more progesterone and less androgen by HOTT cells. The mechanism by which BMP-4 selectively regulates forskolin-induced $17 \alpha$-hydroxylase remains to be elucidated.

\section{$B M P-2$}

Studies on the biological activities of BMP-2 in cultures of primary granulosa cells from sheep ovaries by Souza et al. (2002) led to the proposal that this factor may be involved in preventing spontaneous luteinization, similar to the roles of BMP-4 and -7 uncovered in the rat model (Shimasaki et al., 1999). Specifically, BMP-2 augmented FSH-induced oestradiol synthesis and inhibin A production in granulosa cells isolated from ovine follicles that were $1-3 \mathrm{~mm}$ in diameter. In contrast to the effects of BMP-7 in rats, BMP-2 did not promote mitosis in the ovine granulosa cells (Souza et al., 2002).

\section{BMP-6}

BMP-6 was also shown to exhibit biological activities in rat granulosa cells (Otsuka et al., 2001b). Similar to BMP-4 and -7, BMP-6 was found to be potent in the attenuation of $\mathrm{FSH}$-induced progesterone production; however, in contrast to BMP-4 and $-7, \mathrm{BMP}-6$ did not alter FSH-induced oestradiol production. Consistent with its steroidogenic properties, BMP-6 inhibited FSH-induced stimulation of StAR and P450scc mRNA expression, without affecting 
the expression of P450arom mRNA. Interestingly, BMP-6 also inhibited forskolin-induced progesterone production and the corresponding expression of StAR and P450SCC MRNA, but failed to inhibit progesterone synthesis and steroidogenic enzyme expression induced by 8-Br-cAMP (Otsuka et al., 2001a). A similar inhibition of the expression of mRNA encoding a battery of other FSH-responsive genes including the inhibin-activin subunits $(\alpha, \beta A$ and $\beta B$ ) and the $\mathrm{LH}$ receptor by BMP- 6 was observed when stimulated by forskolin but not when stimulated by 8 -Br-CAMP. These findings indicate that the inhibitory effect of BMP-6 on FSH action is caused by suppression of adenylate cyclase activity. We also found that BMP- 6 lacks mitotic activity on rat granulosa cells. Together, this study provides the first insight into the biological function of BMP-6 in the ovary and demonstrates its unique regulatory mechanism of FSH action.

\section{BMP-15}

Studies using recombinant BMP-15 in rat primary granulosa cells revealed unique and important functions of BMP-15 in ovarian physiology (Otsuka et al., 2000, 2001C; Otsuka and Shimasaki, 2002). First, BMP-15 is a potent stimulator of granulosa cell proliferation (Otsuka et al, 2000). Importantly, the mitotic activity of BMP-15 is independent of FSH, indicating that BMP-15 is directly involved in controlling mitosis in the granulosa cells of preantral follicles during the FSH-independent stages of early folliculogenesis. Second, BMP-15 is a potent inhibitor of FSH receptor expression in granulosa cells (Otsuka et al., 2001c). By inhibiting FSH receptor expression, BMP-15 suppresses the FSH-induced expression of a battery of FSH responsive genes including StAR, P450SCC, 3 $\beta-H S D, L H$ receptor and inhibinactivin subunits $(\alpha, \beta A$ and $\beta B$ ). Although BMP-15 has a similar effect on FSH-induced steroidogenesis to BMP-6 (that is, suppressing progesterone but not oestradiol production), the effects of BMP-15 were due to a reduction in the expression of the FSH receptor in the granulosa cells (Otsuka et $a l ., 2001 \mathrm{c}$ ), and not to the inhibition of adenylate cyclase, as is the case for BMP-6 (Otsuka et al., 2001b). Thus, we suggest that BMP-15 functions as a negative regulator of granulosa cell cytodifferentiation induced by $\mathrm{FSH}$, but as a positive regulator of granulosa cell replication. Third, oocyte-derived BMP-15 and granulosa cell-derived kit ligand form a negative feedback loop in regulating granulosa cell growth (Otsuka and Shimasaki, 2002). Specifically, BMP-15 stimulates kit ligand expression in granulosa cells, whereas kit ligand inhibits BMP-15 expression in oocytes. Interestingly, the blockage of c-kit (kit ligand receptor) signalling in oocytes suppressed BMP-15-induced granulosa cell mitosis, indicating that the oocyte plays a role in the events that govern granulosa cell responses to BMP-15. Therefore, we propose that the mitotic activities of BMP-15 and kit ligand on granulosa cells may depend upon this novel oocyte-granulosa cell communication system. As kit ligand is concomitantly expressed with BMP-15 in the early stages of follicular development, together with the established importance of these two factors in the regulation of preantral follicular development, this novel gametic-somatic cell feedback system may be important in the mechanisms controlling normal folliculogenesis.

We also found that the biological activities of BMP- 15 are blocked by follistatin. This finding is based on the observation that follistatin attenuates the BMP-15 stimulation of granulosa cell proliferation and reverses the BMP-15 inhibition of FSH receptor mRNA expression and subsequent progesterone production (Otsuka et al., 2001a). The antagonistic action of BMP-15 and follistatin was confirmed by using a surface plasmon resonance biosensor. Thus, the emerging scenario is that the precise regulation of the bioavailability of BMP-15 in the follicular microenvironment may be determined by the novel BMP-15 binding protein, follistatin. 


\section{GDF-9}

Although GDF-9 shares the highest homology with BMP-15 and exhibits a similar oocytespecific expression pattern to BMP-15, studies, mainly by the Hsueh, and Matzuk and coworkers, have demonstrated that the biological activities of GDF-9 are distinct from those of BMP-15. In rat whole ovarian follicle cultures, GDF-9 was first shown to be effective in stimulating preantral follicle growth (Hayashi et al., 1999). Cultures of rat granulosa cells collected from early antral and preovulatory follicles were used to show that GDF-9 also promotes granulosa cell proliferation, and inhibits $\mathrm{FSH}$-induced steroidogenesis and $\mathrm{LH}$ receptor expression (Vitt et al,, 2000a). On the basis of the finding that GDF-9 affects neither CAMP production nor steroidogenesis induced by forskolin, GDF-9 inhibition of FSH action was postulated to occur as a result of the modulation of FSH receptor content or FSH receptor coupling to Gs protein (Vitt et al., 2000a). In isolated mouse ovarian cells, GDF-9 was shown to regulate diverse processes and gene expression during the preovulatory stage including the enhancement of FSH-induced cumulus cell expansion, the expression of hyaluronan synthase 2 (HAS2) and cyclooxygenase 2 (Cox2) as well as the inhibition of $\mathrm{LH}$ receptor and urokinase plasminogen activator expression (Elvin et al., 1999b). In contrast to the inhibition of FSH-induced steroidogenesis, GDF-9 alone increased progesterone production in cumulus granulosa cells by stimulating the expression of an intrinsic prostaglandin $E_{2}-E P_{2}$ receptor signalling pathway (Elvin et al, 2000b).

Another important function of GDF-9 involves its action on kit ligand expression. In contrast to the stimulatory action of BMP-15 observed in rats (Otsuka and Shimasaki, 2002), GDF-9 suppresses the steady-state mRNA content of kit ligand in mouse granulosa cells (Joyce et al., 2000). These data corroborate earlier findings that in GDF-9 null mice there is an increase in ovarian kit ligand (Elvin et al., 1999b), Intriguingly, studies on mice demonstrated that the addition of partly grown oocytes to granulosa cell cultures caused an increase in kit ligand mRNA expression, whereas the addition of fully grown oocytes had the opposite effect (Joyce et al., 1999). Thus, the effect of oocytes on granulosa cell kit ligand expression depends on the developmental stages of the oocytes. Although both GDF-9 and BMP-15 mRNA and protein are detectable in oocytes throughout folliculogenesis, nothing is known about the temporal secretion pattern of the biologically active forms of these growth factors. On the basis of the opposing effects of GDF-9 and BMP-15 on kit ligand expression, coupled with the opposing effects of partly and fully grown oocytes on kit ligand expression, it can be hypothesized that the partly grown oocytes secrete primarily BMP-15 (a kit ligand stimulatory factor), whereas fully grown oocytes secrete primarily GDF-9 (a kit ligand-inhibitory factor) (Otsuka and Shimasaki, 2002).

Vitt et al. (2000b) were the first to demonstrate the effect of GDF-9 in folliculogenesis in vivo. Intraperitoneal injections of GDF-9 into immature rats promoted the progression of primordial and primary follicles to small preantral follicles and caused an increase in the expression of CYP17, a theca cell marker. Therefore, GDF-9, similar to BMP-7, has the potential to be used as a therapeutic agent to stimulate early follicular development. The clinical relevance of this idea is emphasized by organ culture experiments in which GDF-9 promoted recruitment and early preantral follicle growth in human ovaries (Hreinsson et al., 2002).

Our recent study indicated that aberrant expression of GDF-9 may be associated with pathological ovarian dysfunction in women (Teixeira Filho et al., 2002). In this study, the expression of GDF-9 and BMP-15 was investigated by in situ hybridization using sections of ovaries from polycystic ovary syndrome (PCOS) and polycystic ovary (PCO) patients. These studies revealed that the expression of GDF-9 mRNA is delayed and reduced in the ovaries of PCOS and PCO patients during the growth and differentiation phase. In contrast, there 
was no observable difference in the expression pattern of BMP-15 mRNA in PCOS and PCO ovaries as compared with normal ovaries. Further investigations will be required to determine whether the reduced GDF-9 mRNA causes the follicular arrest in PCOS/PCO or whether they are simply an epiphenomenon of another primary abnormality.

\section{Aberrant BMP system in female reproduction}

These in vivo and in vitro studies clearly indicate that the BMP system appears to be of primary importance in early follicle recruitment. The recent elucidation of the reproductive phenotypes of animals that have mutations (either naturally occurring mutations or 'gene knockouts' by targeted deletion) of the genes encoding various components of the BMP system has provided significant breakthroughs in our understanding of the physiological importance of the BMP system in ovarian function. Of particular interest are mutations that result in phenotypic abnormalities which are, for the most part, restricted to female reproductive function. There are four examples of BMP system gene mutations that have ovary-specific phenotypes included: (i) GDF-9 knockout mice, (ii) Inverdale and Hanna ewes which have point mutations in the bmp15 gene, (iii) BMP-15 knockout mice and (iv) Booroola ewes which have a mutation in the bmprlb gene.

\section{GDF-9 null mice}

Dong et al. (1996) established a line of mice that are deficient in the gene encoding GDF-9 and provided the first insight into a BMP-related gene that displays selective effects on early ovarian folliculogenesis. Male mice that were heterozygous and homozygous for the deletion of the gdfg gene were viable and fertile with no clear phenotype, as were heterozygous females. In contrast, female homozygous GDF-9 null mice were viable but, importantly, they were completely infertile due to a block in folliculogenesis at the primary follicle stage.

The pathological features of these homozygous GDF-9 null mice have been studied extensively and these studies have provided insight into the role of GDF-9 in vivo. Circulating concentrations of FSH and LH in GDF-9 deficient female mice are high (three- and twofold, respectively) compared with controls (Dong et al., 1996). Follicles in GDF-9 deficient ovaries fail to progress beyond the primary stage as a result of impaired proliferation of the granulosa cells, but also fail to undergo apoptosis. It also appears that the follicles in GDF-9 deficient mice fail to develop a theca cell layer (Elvin et al., 1999b). Expression of kit ligand and inhibin $\alpha$ is high in ovaries from GDF-9 deficient mice indicating that GDF-9 may play a role in suppressing these important ovarian factors.

\section{Inverdale and Hanna ewes}

Domestic sheep normally ovulate one to two oocytes giving rise to single and twin pregnancies. A few strains of sheep that consistently have an increased ovulation rate have been identified (Montgomery et al., 1992). Two of these strains are called Inverdale (FecX') and Hanna $\left(\mathrm{FecX}^{\mathrm{H}}\right)$ ewes. Genetic analysis of these unrelated families of sheep demonstrated that the phenotype of these prolific ewes was determined by a single putative gene on the $X$ chromosome (Davis et al,, 1991). Females that carry one copy of the gene have increased ovulation and lambing rates, whereas females with two copies of the gene are infertile with 'streak' ovaries (Davis et al., 1992). Male carriers of the gene are unaffected. Further genetic analysis revealed that both the Inverdale and Hanna phenotypes were correlated with single point mutations in the bmp 15 gene. Inverdale ewes have a $\mathrm{T}$ to A nucleotide substitution that results in a substitution of the valine with an aspartic acid at position 31 of mature BMP-15 
(Galloway et al., 2000). The region of the BMP-15 protein affected by this substitution is highly conserved between species. It was proposed by these workers that the substitution of the hydrophobic valine with a negatively charged aspartic acid may inhibit the ability of the BMP-15 subunits to form dimers, thus making the BMP-15 inactive. As discussed above, it is not yet known whether BMP-15 forms non-covalent dimers; therefore, this hypothesis has not been confirmed. In Hanna ewes, there is a C to T nucleotide substitution that results in a premature stop codon at amino acid residue 23 of the mature BMP-15 protein (Galloway etal., 2000).

The finding that sheep lacking intact BMP-15 (Fec $X^{1} / F e c X^{1}, F e c X^{H} / F e c X^{H}$ and $F e c X^{1} / F e c X^{H}$ ) are infertile with a block at the primary stage of folliculogenesis demonstrates the necessity of this growth factor for folliculogenesis in sheep. The increased ovulation rates in heterozygous Inverdale and Hanna mutants led to the proposal that BMP-15 affects fertility in a biphasic manner, and low doses increased fertility and the absence of BMP-15 caused infertility (Galloway et al., 2000). Our in vitro experiments with recombinant BMP-15 provide some potential insight into understanding the mechanisms of the Inverdale-Hanna phenotype (Otsuka et al., 2000, 2001c; Otsuka and Shimasaki, 2002). The phenotypic features of these BMP-15 mutant ewes and the correlating biological actions of BMP-15 that may be impaired or abolished in the heterozygous or homozygous mutants, respectively, are summarized (Table 1). In the homozygous mutants, the lack of the proliferative properties of BMP-15 (Otsuka et al., 2000 ) could prevent the division of granulosa cells, which is necessary for the transition from primary to secondary follicles. In addition, the lack of BMP-15 stimulation of kit ligand expression may also cause impaired growth of primary follicles (Otsuka and Shimasaki, 2002) because kit ligand plays important roles in oogenesis and folliculogenesis during early follicular development. In contrast, the finding that BMP-15 attenuates FSH-induced granulosa cell differentiation by inhibiting FSH receptor expression (Otsuka et al., 2001c) is consistent with the increased numbers of follicles selected for ovulation in the heterozygous sheep, which presumably have lower amounts of bioactive BMP-15. This hypothesis is supported by the following physiological features of the heterozygous Inverdale and Hanna ewes reported by Shackell et al. (1993): (i) there are more healthy oestrogenic follicles than in wildtype ewes (which is consistent with increased differentiation of granulosa cells than would be expected in a low BMP-15 environment); (ii) these developing follicles are smaller than those of wild-type ewes owing to fewer granulosa cells (which could be expected to be caused by the reduction of granulosa cell proliferation in a low BMP-15 environment); (iii) the follicles develop $\mathrm{LH}$ responsiveness at smaller sizes (which is probably due to increased FSH receptor expression in a low BMP-15 environment); and (iv) the corpora lutea of the heterozygous mutant sheep are smaller than those in wild-type ewes (which could occur because smaller follicles ovulate due to higher FSH sensitivity caused by lower BMP-15).

\section{BMP-15 null mice}

The establishment of BMP-15 null mice by targeted deletion of the bmp15 gene provided the role of BMP-15 in female reproduction in mice (Yan et al, 2001). Similar to the Inverdale and Hanna sheep, male BMP-15 null mice are fertile with no clear abnormal phenotype. Female mice heterozygous for bmp15 gene deletion also have normal fertility. Females homozygous for deletions in the bmp-15 gene, although fertile, had consistently fewer pups per litter and numbers of litters per month. These mice also developed histopathological ovarian defects including multiple oocytes in a single follicle. Female mice homozygous for deletions in BMP-15 had only decreased fertility, which is different from homozygous Inverdale and Hanna ewes which are infertile. This finding demonstrates the difference 
Table 1. Characteristics and physiological basis of the aberrant phenotype of bone morphogenetic protein 15 (BMP-15) mutant ewes (inverdale and Hanna) and the correlating biological activity of BMP-15

Features of phenotype

\section{Homozygotes}

Infertility due to arrest of follicular development at the primary stage

\section{Heterozygotes \\ Lower number of granulosa cells in follicles of com- ponent stages of developing follicles \\ Higher number of oestro- genic follicles \\ Higher $\mathrm{LH}$ responsiveness}

Increased ovulation rate

Smaller corpora lutea
Loss of GC mitosis

Correlating biological activity of BMP-15

BMP-15 is a granulosa cell
Reduced granulosa cell mitosis

Increased sensitivity to FSH

Higher FSH-induced expression of iH receptors due to increased $\mathrm{FSH}$ sensitivity

Increase in FSH-induced differentiation of follicles due to increased FSH sensitivity

Ovulation of oocytes from smaller follicles due to increased FSH sensitivity mitogen and stimulates kit ligand (a granulosa cell mitogen) expression

BMP-15 stimulates granulosa cell mitosis

BMP-15 suppresses FSH receptor expression

BMP-15 suppresses FSH receptor expression

BMP-15 suppresses FSH receptor expression

BMP-15 suppresses FSH receptor expression

between sheep and mice with respect to the importance of BMP-15. When using these animals as models to understand fertility, it is important to note that mice are polyovulatory, whereas sheep are generally mono-ovulatory. Given that BMP-15 seems to play a central role in follicle recruitment and ovulation quota, the differences of the responses to the lack of BMP-15 between sheep and mice may be involved in defining the normal ovulation rate in these species.

The double mutant mice that are homozygous deficient in BMP-15 and heterozygous deficient in GDF-9 have more severe reductions in fertility compared with mice which are only homozygous deficient in BMP-15 (Yan et al., 2001). This finding, when taken together with the similar spatial and temporal expression patterns and the sequence homology between GDF-9 and BMP-15, led to the proposal that there are physiologically important interactions between these two factors. These interactions could involve the formation and secretion of GDF-9-BMP-15 heterodimers from the oocyte or interactions with the same receptors on granulosa cells.

\section{Booroola ewes}

The Booroola, similar to the Inverdale and Hanna, is a strain of sheep that has been maintained as a result of its high fecundity. On the basis of Mendelian genetic analysis, it was proposed that the Booroola phenotype was caused by a single putative gene $\left(\mathrm{Fec}^{\mathrm{B}}\right.$ ) and that ewes that carry one copy of the gene (heterozygotes) have increased ovulation and lambing rates, whereas those that carry two copies of the gene (homozygotes) have ovulation and lambing rates that are even higher than the heterozygotes (Montgomery et al., 1992). Recently, three laboratories independently identified that the Booroola phenotype 
Table 2. Characteristics and physiological basis of the aberrant phenotype of ALK-6 mutant ewes (Booroola) and the correlating biological activity of bone morphogenetic protein 6 (BMP-6)

\begin{tabular}{|c|c|c|}
\hline Features of phenotype & Physiological basis of features & $\begin{array}{l}\text { Correlating biological activity } \\
\text { of } \mathrm{BMP}-6\end{array}$ \\
\hline $\begin{array}{l}\text { Higher progesterone, but not } \\
\text { oestradiol, induced by FSH } \\
\text { and LH }\end{array}$ & $\begin{array}{l}\text { Selective inhibition of progesterone } \\
\text { synthesis }\end{array}$ & $\begin{array}{l}\text { BMP-6 decreases progesterone } \\
\text { synthesis without affecting } \\
\text { oestradiol synthesis }\end{array}$ \\
\hline $\begin{array}{l}\text { Increased } \mathrm{FSH} \text {-induced } \\
\text { responsiveness to CAMP }\end{array}$ & Enhanced FSH activity & $\begin{array}{l}\text { BMP- } 6 \text { inhibits adenylate } \\
\text { cyclase activity }\end{array}$ \\
\hline $\begin{array}{l}\text { Granulosa cells are more sensitive } \\
\text { to FSH without a change in FSH } \\
B_{\max } \text { and } K_{\mathrm{d}} \text { values }\end{array}$ & $\begin{array}{l}\text { Enhanced FSH activity without } \\
\text { altering FSH receptor number } \\
\text { and affinity }\end{array}$ & $\begin{array}{l}\text { BMP-6 inhibits adenylate cyclase } \\
\text { activity without changing FSH } \\
\text { receptor expression }\end{array}$ \\
\hline $\begin{array}{l}\text { Earlier onset of pre-ovulatory } \\
\text { follicular maturation }\end{array}$ & $\begin{array}{l}\text { Increased FSH activity and } \\
\text { subsequent increased sensitivity } \\
\text { to LH (precocious follicle } \\
\text { maturation) }\end{array}$ & $\begin{array}{l}\text { BMP-6 inhibits adenylate } \\
\text { cyclase activity }\end{array}$ \\
\hline $\begin{array}{l}\text { Normal number of granulosa cells } \\
\text { in preantral follicles }\end{array}$ & $\begin{array}{l}\text { Normal mitotic index of granulosa } \\
\text { cells }\end{array}$ & $\begin{array}{l}\text { BMP- } 6 \text { does not affect granulosa } \\
\text { cell mitosis }\end{array}$ \\
\hline
\end{tabular}

corresponds to a single point mutation in the intracellular kinase domain of the BMPR-IB gene (Mulsant el al., 2001; Souza et al., 2001; Wilson et al., 2001). The mechanisms by which this mutation causes an increase in fertility and the endogenous ligands that are involved have not yet been established. Nonetheless, BMP and BMP-related growth factors that are expressed in the ovary, including BMP-6, BMP-7, BMP-4 and GDF-5, have been shown to bind the BMPR-IB in various types of cell (Ebisawa et al., 1999; Miyazono, 2001). Although the receptors for BMP-15 and GDF-9 have not yet been identified, the BMPR-IB receptor is a candidate for these ovarian factors.

On the basis of the biological activities of recombinant proteins in vitro, we propose that the phenotype of the Booroola ewe is most consistent with the ablation of the biological effects of BMP-6 (Otsuka et al., 2001) as summarized (Table 2). Aspects of the Booroola phenotype that support this hypothesis include the following. First, when cultured for $48 \mathrm{~h}$, granulosa cells from Booroola ewes produce higher amounts of progesterone but not oestradiol when compared with wild-type granulosa cell cultures (McNatty et al., 1986). Second, Booroola follicles are more sensitive to $\mathrm{FSH}$, but this response is not caused by increases in FSH binding capacity to granulosa cells (McNatty et al., 1989). These findings are consistent with the evidence that BMP-6 inhibits FSH sensitivity by inhibiting adenylate cyclase activity, but has no effect on FSH receptor expression. In addition, consistent with the inability of BMP- 6 to stimulate granulosa cell mitosis, it seems that the Booroola mutation in the BMPR-IB does not prevent granulosa cell mitosis. The finding that supports this hypothesis is that homozygous Booroola ewes have high ovulation rates in contrast to homozygous Inverdale and Hanna ewes which have a block in folliculogenesis at the primary stage.

\section{Conclusion}

The recent investigations of the expression and biological activities of various BMP ligands and the receptor signalling pathway in the ovary of a variety of mammals have uncovered numerous important roles for an intrinsic BMP system in the regulation of folliculogenesis and female fertility. A careful comparison of individual BMPs in a particular species reveals that there are many overlapping biological effects of the BMPs. However, each BMP does seem to have a 
unique role in regulating follicle development. An emerging common theme is that the BMPS in the ovary are of paramount importance in regulating follicle growth and development. Furthermore, the ovary-specific phenotypes of animals with mutations in various components of the BMP system (GDF-9 knockout mice, BMP-15 knockout mice, Inverdale ewe, Hanna ewe and Booroola ewe) make the BMP system an attractive target for therapeutic regimens designed to alter fertility at the levels of granulosa cell proliferation and FSH responsiveness.

This work was supported in part by NIH Grant R01 HD41494, NICHD/NIH through cooperative agreement [U54HD12303] as part of Specialized Cooperative Centers Program in Reproduction Research and the UCSD Academic Senate (RA 882M). R. K. Moore was supported by NIH Fellowship Grant F32 HD41320-01 and F. Otsuka was supported by The Lalor Foundation Fellowship. We apologize to those authors whose work we were not able to cite because of space constraints.

\section{References}

Aaltonen J, Laitinen MP, Vuojolainen K ef al. (1999) Human growth differentiation factor 9 (GDF-9) and its novel homolog GDF-9B are expressed in oocytes during early folliculogenesis Journal of Clinical Endocrinology and Metabolism 842744 2750

Bodensteiner $\mathrm{KJ}$, Clay $\mathrm{CM}$, Moeller $\mathrm{CL}$ and Sawyer $\mathrm{HR}$ (1999) Molecular cloning of the ovine growth/ differentiation factor 9 gene and expression of growth/differentiation factor-9 in ovine and bovine ovaries Biology of Reproduction 60 381-386

Davis GH, McEwan IC, Fennessy PF, Dodds KG and Farquhar PA (1991) Evidence for the presence of a major gene influencing ovulation rate on the $X$ chromosome of sheep Biology of Reproduction 44620 624

Davis GH, McEwan JC, Fennessy PF, Dodds KG, McNatty KP and O WS (1992) Infertility due to bilateral ovarian hypoplasia in sheep homozygous (FecXI FecXI) for the Inverdale prolificacy gene located on the X chromosome Biology of Reproduction 46 636-640

Dong J, Albertini DF, Nishimori K, Kumar TR, Lu N and Matzuk M (1996) Growth differentiation factor 9 is required during early ovarian folliculogenesis Nature $383531-535$

Dooley CA, Attia GR, Rainey WE, Moore DR and Carr BR (2000) Bone morphogenetic protein inhibits ovarian androgen production Journal of Clinical Endocrinology and Metabolism 85 3331-3337

Dube JL, Wang P, Elvin J, Lyons KM, Celeste Al and Matzuk MM (1998) The bone morphogenetic protein 15 gene is $X$-linked and expressed in oocytes Molecular Endocrinology 12 1809-1817

Ebisawa T, Tada K, Kitajima I, Tojo K, Sampath TK, Kawabata M, Miyazono K and Imamura T (1999) Characterization of bone morphogenetic protein6 signaling pathways in osteoblast differentiation Journal of Cell Science 112 3519-3527.

Elvin JA, Clark AI, Wang P, Wolfman NM and Matzuk MM (1999a) Paracrine actions of growth differenti- ation factor-9 in the mammalian ovary Moleculat Endocrinology 13 1035-1048

Elvin JA, Yan C, Wang P, Nishimori $K$ and Matzuk MM (1999b) Molecular characterization of the follicle deiects in the growth differentiation factor 9deficient ovary Molecular Endocrinology 13 10181034

Elvin IA, Yan C and Matzuk MM (2000a) Oocyteexpressed TCF- $\beta$ superfamily members in female fertility Molecular and Cellular Endocrinology $\mathbf{1 5 9}$ $1-5$

Elvin JA, Yan C and Matzuk MM (2000b) Growth differentiation factor 9 stimulates progesterone synthesis in granulosa cells via a prostaglandin $E_{2} / E P_{2}$ receptor pathway Proceedings National Academy of Sciences USA $9710288-10293$

Erickson GF and Shimasaki S (2000) The role of the oocyte in folliculogenesis Trends in Endocrinology and Metabolism 11 193-198

Fitzpatrick SL, Sindoni DM, Shughrue PJ, Lane MV, Merchenthaler II and Frail DE (1998) Expression of growth differentiation factor 9 messenger ribonucleic acid in ovarian and non-ovarian rodent and human tissues Endocrinology 139 2571-2578

Galloway SM, MCNatty KP, Cambridge LM et al. (2000) Mutations in an oocyte-derived growth factor gene (BMP15) cause increased ovulation rate and infertility in a dosage-sensitive manner Nature Genetics 25 279-283

Graff JM, Bansal A and Melton DA (1996) Xenopus Mad proteins transduce distinct subsets of signals for the TGF beta superfamily Cell $85 \quad 479-487$

Griffith DL, Keck PC, Sampath TK, Rueger DC and Carlson WD (1996) Three-dimensional structure of recombinant human osteogenic protein 1: structural paradigm for the transtorming growth factor beta superfamily Proceedings National Academy of Sciences USA 93 878-883

Hayashi M, McGee EA, Min G, Klein C, Rose UM, Van Duin M and Hsueh AJW (1999) Recombinant growth differentiation factor 9 (GDF-9) enhances 
growth and differentiation of cultured early ovarian follicles Endocrinology 140 1236-1244

Heldin C-H, Miyazono K and ten Dijke P (1997) TGF- $\beta$ signaling from cell membrane to nucleus through SMAD proteins Nature $390465-471$

Hino J, Takao M, Takeshita N, Konno $\mathrm{Y}$, Nishizawa T, Matsuo $\mathrm{H}$ and Kangawa $\mathrm{K}$ (1996) CDNA cloning and genomic structure of human bone morphogenetic protein-3b (BMP-3b) Biochemical and Biophysical Research Communications 223 304-310

Hogan BLM (1996) Bone morphogenetic proteins: multifunctional regulators of vertebrate development Genes and Development 10 1580-1594

Hreinsson JG, Scott JE, Rasmussen C, Swahn ML, Hsueh AJW and Hovatta $O$ (2002) Growth differentiation factor-9 promotes the growth, development, and survival of human ovarian follicles in organ culture Journal of Clinical Endocrinology and Metabolism $87316-321$

Jaatinen R, Rosen V, Tuuri T and Ritvos O (1996) Identification of ovarian granulosa cells as a novel site of expression for bone morphogenetic protein-3 (BMP3/osteogenin) and regulation of BMP-3 messenger ribonucleic acids by chorionic gonadotropin in cultured human granulosa-luteal cells Joumal of Clinical Endocrinology and Metabolism 81 3877-3882

Jaatinen $\mathrm{R}$, Laitinen $\mathrm{M}$, Vuojolainen $\mathrm{K}$, Aaltonen I, Louhio $\mathrm{H}$, Heikinheimo K, Lehtonen $\mathrm{E}$ and Ritvos $\mathrm{O}$ (1999) Localization of growth differentiation factor9 (GDF-9) mRNA and protein in rat ovaries and CDNA cloning of rat GDF-9 and its novel homolog GDF-9B Molecular and Cellular Endocrinology 156 189-193

Joyce IM, Pendola FL, Wigglesworth $\mathrm{K}$ and Eppig JI (1999) Oocyte regulation of kit ligand expression in mouse ovarian follicles Developmental Biology 214 342-353

Joyce IM, Clark AT, Pendola FL and Eppig JJ (2000) Comparison of recombinant growth differentiation factor-9 and oocyte regulation of KIT ligand messenger ribonucleic acid expression in mouse ovarian follicles Biology of Reproduction $631669-1675$

Kawabata M and Miyazono K (2000) Bone morphogenetic proteins. In Skeletal Growth Factors pp 269-290 Ed. E Canalis. Lippincott Williams \& Wilkins, Philadelphia

Kingsley DM (1994) The TGF- $\beta$ superfamily: new members, new receptors, and new genetic tests of function in different organisms Genes and Development 8 133-146

Laitinen M, Vuojolainen K, Jaatinen R, Ketola I,

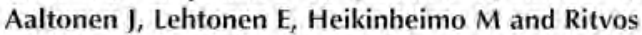
O (1998) A novel growth differentiation factor 9 (GDF-9) related factor is co-expressed with GDF-9 in mouse oocytes during folliculogenesis Mechanisms of Development 78 135-140

Lee W, Otsuka F, Moore RK and Shimasaki S (2001) The effect of bone morphogenetic protein-7 on follicu- logenesis and ovulation in the rat Biology of Reproduction 65 994-999

Liu F, Ventura F, Doody J and Massagué J (1995) Human type II receptor for bone morphogenic proteins (BMPs): extension of the two-kinase receptor model to the BMPs Molecular and Cellular Biology $153479-3486$

Lyons KM, Pelton RW and Hogan BLM (1989) Patterns of expression of murine Vgr-1 and BMP-2a RNA suggest that transforming growth factor-b-like genes coordinately regulate aspects of embryonic development Genes and Development 3 1657-1668

Lyons KM, Pelton RW and Hogan BL (1990) Organogenesis and pattern formation in the mouse: RNA distribution patterns suggest a role for bone morphogenetic protein-2A (BMP-2A) Development $109833-$ 844

McGrath SA, Esquela AF and Lee S-J (1995) Oocyte specific expression of growth/differentiation factor-9 Molecular Endocrinology 9 131-136

McNatty KP, Kieboom LE, McDiarmid J, Heath DA and Lun S (1986) Adenosine cyclic $3^{\prime}, 5^{\prime}$-monophosphate and steroid production by small ovarian follicles from Booroola ewes with and without a fecundity gene Journal of Reproduction and Fertility 76 471-480

McNatty KP, Lun S, Heath DA, Hudson NL, O'Keeffe LE and Henderson KM (1989) Binding characteristics of ${ }^{125}$ I-labelled human FSH to granulosa cells from Booroola ewes which were homozygous, heterozygous or non-carriers of a major gene(s) influencing their ovulation rate Journal of Reproduction and Fertility $86.27-38$

McPherron AC and Lee S-J (1993) GDF-3 and GDF-9: two new members of the transforming growth factorb superfamily containing a novel pattern of cysteines Journal of Biological Chemistry 268 3444-3449

Massagué 1, Attisano L and Wrana JL (1994) The TGF-b family and its composite receptors Trends in Cellular Biology 4 172-178

Miyazono K, Kusanagi K and Inoue H (2001) Divergence and convergence of TGF-beta/BMP signaling lournal of Cellular Physiology $187265-276$

Montgomery GW, McNatty KP and Davis GH (1992) Physiology and molecular genetics of mutations that increase ovulation rate in sheep Endocrine Reviews $13309-328$

Mulsant P, Lecerf F, Fabre S et al. (2001) Mutation in bone morphogenetic protein receptor-1B is associated with increased ovulation rate in Booroola Merino ewes Proceedings National Academy of Sciences USA 98 5104-5109

Otsuka F and Shimasaki S (2002) A negative feedback system between oocyte bone morphogenetic protein 15 and granulosa cell kit ligand: its role in regulating granulosa cell mitosis Proceedings National Academy of Sciences USA 99 8060-8065

Otsuka F, Yao Z, Lee TH, Yamamoto S, Erickson GF and Shimasaki S (2000) Bone morphogenetic protein-15: 
identification of target cells and biological functions Journal of Biological Chemistry 27539523 39528

Otsuka F, Moore RK, lemura S-I, Ueno $\mathrm{N}$ and Shimasaki S (2001a) Follistatin inhibits the function of the oocyte derived factor BMP-15 Biochemical and Biophysical Research Communications 289 961-966

Otsuka F, Moore RK and Shimasaki S (200Tb) Biological function and cellular mechanism of bone morphogenetic protein 6 in the ovary Journal of Biological Chemistry 276 $32889-32895$

Otsuka F, Yamamoto S, Erickson GF and Shimasaki $\mathrm{S}$ (2001c) Bone morphogenetic protein-15 inhibits follicle-stimulating hormone ( $\mathrm{FSH}$ ) action by suppressing FSH receptor expression Journal of Biological Chemistry $27611387-11392$

Schlunegger MP and Grütter MG (1992) An unusual feature revealed by the crystal structure at $2.2 \mathrm{~A}$ resolution of human transforming growth factor-b2 Nature $358430-434$

Shackell GH, Hudson NL, Heath DA, Lun S, Shaw L, Condell L, Blay LR and McNatty KP (1993) Plasma gonadotropin concentrations and ovarian characteristics in Inverdale ewes that are heterozygous for a major gene (FecX1) on the X chromosome that inFluences ovulation rate Biology of Reproduction 48 $1150-1156$

Shimasaki S, Zachow RJ, Li D, Kim H, Jemura S-I, Ueno N, Sampath K, Chang RJ and Erickson GF (1999) A functional bone morphogenetic protein system in the ovary Proceedings National Academy of Science USA $967282-7287$

Souza CJH, MacDougall C, Campbell BK, McNeilly AS and Baird DT (2001) The Booroola (FecB) phenotype is associated with a mutation in the bone morphogenetic receptor type 1B (BMPR1B) gene lournal of Endocrinology 169 R1-R6

Souza CJH, Campbell BK, McNeilly AS and Baird DT (2002) Effect of bone morphogenetic protein 2 (BMP2) on oestradiol and inhibin A production by sheep granulosa cells, and localization of BMP receptors in the ovary by immunohistochemistry Reproduction (Cambridge) 123 363-369
Takao M, Hino J, Takeshita N, Konno Y, Nishizawa T, Matsuo $\mathbf{H}$ and Kangawa K (1996) Identification of rat bone morphogenetic protein-3b (BMP-3b), a new member of BMP-3 Biochemical and Biophysical Research Communications 219 656-662

Teixeira Filho FL, Baracat EC, Lee TH, Suh CS, Matsui M, Chang RJ, Shimasaki S and Erickson GF (2002) Aberrant expression of growth differentiation factor-9 in oocytes of women with polycystic ovary syndrome Journal of Clinical Endocrinology and Metabolism $871337-1344$

Thomsen GH (1996) Xenopus mothers against decapentaplegic is an embryonic ventralizing agent that acts downstream of the BMP-2/4 receptor $D e$. velopment 122 2359-2366

Vitt UA, Hayashi M, Klein C and Hsueh AJW (2000a) Growth differentiation factor 9 stimulates proliferation but suppresses the follicle-stimulating hormoneinduced differentiation of cultured granulosa cells from small antral and preovulatory rat follicles Biology of Reproduction $62370-377$

Vitt UA, McGee EA, Hayashi M and Hsueh AJW (2000b) In vivo treatment with GDF-9 stimulates primordial and primary follicle progression and theca cell marker CYP17 in ovaries of immature rats Endocrino logy $1413814-3820$

Vitt UA, Hsu SY and Hsueh AJW (2001) Evolution and classification of cystine knot-containing hormones and related extracellular signaling molecules Molecular Endocrinology 15 681-694

Wilson T, Wu X-Y, Juengel JL et al. (2001) Highly prolific Booroola sheep have a mutation in the intracellular kinase domain of bone morphogenetic protein IB receptor (ALK-6) that is expressed in both oocytes and granulosa cells Biology of Reproduction 641225 1235

Wozney JM, Rosen V, Celeste AJ, Mitsock LM, Whitters MJ, Kriz RW, Hewick RM and Wang EA (1988) Novel regulators of bone formation: molecular clones and activities Science 242 1528-1534

Yan C, Wang P, DeMayo J et al. (2001) Synergistic roles of bone morphogenetic protein 15 and growth differentiation factor 9 in ovarian function Molecular Endocrinology $15854-866$ 